\title{
COMPARISON OF SOME SAMPLING METHODS FOR ADULTS OF Scymnus syriacus AND Coccinella undecimpunctata (COLEOPTERA: COCCINELLIDAE) ON SOYBEAN PLANTINIONS IN MANSOURA DISTRICT.
}

Abdel-Salam, A. H. ${ }^{1}$; A. M. Abou-El Naga'; A. A. Ghanim ${ }^{1}$; M. E. El-Naggar ${ }^{2}$ and A. M. Mohamed ${ }^{2}$

1- Economic Entomology Department, Faculty of Agriculture, Mansoura University, Mansoura 35516, Egypt.

E-mail: adhabdelus@yahoo.com.

2- Plant Protection Research Institute, Agricultural Research Center, Ministry of Agriculture, Egypt.

\begin{abstract}
Samplings of $S$. syriacus and $C$. undecimpunctata were carried out in Mansoura district, Dakahlia Governorate during 2008 and 2009 seasons. We examined several types of yellow sticky cards (vertically oriented cylinder, vertically oriented, two-sided traps and vertically oriented, one-sided traps) and sweep-net thin indirectly measured adult abundance based on activity and visual examination and whole-plant methods as two direct count sampling methods based on the census of adult on or from the plant.

The count of predator, $S$. syriacus was highly significantly effect by sampling methods. Sweep-net count more significant adult of $S$. syriacus than the other sampling methods during 2008 and 2009 seasons. Furthermore, in 2008 season, there were no significant notes between one sided sticky trap and whole-plant. In addition, there was no significant between cylinder sticky trap and two-sided sticky trap. In 2009 season, there was no significant between cylinder sticky trap, one sided sticky trap, and visual examination.

The relative variation of the sweep-net and one-sided sticky trap methods were significantly less than the other methods for sampling $S$. syriacus. Therefore, it is the optimum sampling methods and indicated greater precision for sampling $S$. syriacus. Sweep-net recorded the highest RNP compared with the other sampling methods. This indicated thin the sweep-net is the greater sampling efficiency.

The count of $C$. undecimpunctata was highly significantly effect by sampling methods in 2008 and 2009 seasons. Visual examination count more insects than sweep-net and whole-plant during 2008 and 2009 seasons. Visual examination had the lowest associated RV value in the first and second seasons (10.90 and 9.61, respectively). Visual examination had the highest calculated RNP value (most efficient) compared with all other sampling methods in the first and second seasons.
\end{abstract}

\section{INTRODUCTION}

Coccinellids are potentially important predatory insect group found throughout the world on many economic crops. Some species may have a significant role in biological control of aphid species, whiteflies, and other softbodied insects (El-Adl et al., 1988; Parajulee et al.,1997; Slosser et al.,1998).

Today, biological control is an increasingly important component of integrated pest management (IPM) programs for agriculture as well as for urban environment. Therefore, techniques for mass production of some predators and parasitoids may be relatively help in solving the problem of 
insect pests on soybean and reduce the hazard of pesticides to human and environment in Egypt. The role of the predacious insects in suppressing the population of the main insect pests of soybean and other crop has been reported by several investigators (El-Adl et al.,1988). Biological control can only be applied in the most efficient way if sampling techniques give reasonably precise estimates of pest densities. Colored sticky traps have been widely used as flight traps to monitor predator population in many agroecosystem (Parajulee and Phillips, 1995; Mensah, 1997; Weston and Barney, 1998).

However, scanty intention has been paid to compare of sampling methods of coccinellids. Therefore, the objective of this study was to compare sampling method techniques of $\mathrm{S}$. syriacus and $\mathrm{C}$. undecimpunctata adults on soybean plantations in Mansoura district.

\section{MATERIALS AND METHODS}

Samplings of $S$. syriacus and C. undecimpunctata were carried out in Mansoura district, Dakahlia Governorate during 2008 and 2009 seasons. Several types of yellow sticky cards, and sweep-net thin indirectly measured adult abundance based on activity and visual examination (leave-turn method) and whole-plan methods as two direct count sampling methods based on the census of adult on or from the plant.

\section{Sampling techniques:}

\section{Yellow sticky traps:}

Three basic types of yellow sticky traps were evaluated during the 2008-2009 seasons; vertically oriented cylinder, vertically oriented, two-sided traps and vertically oriented, one-sided traps. The height and placement of the traps relative to the field were varied over the study. The cylinder traps was made by wrapping a sticky trap $(22$ by $10 \mathrm{~cm})$ around a plastic pipe thin was then placed on a wooden stake. The two-sided trap measured (11 by 10 $\mathrm{cm})$ and was positioned vertically on a wooden stake. The one-sided trap measured $(11$ by $10 \mathrm{~cm})$ and was oriented horizontally with the sticky surface facing skyward. The one-and two-sided traps were stapled to plastic pot stakes and then attached to wooden stakes in the field. The stakes were placed within the row and plants were cleared as necessary to ensure thin leaves did not become entangled on the sticky surface. The trap height was adjusted as needed throughout the season.

\section{Visual examination (leaf-turn method):}

The visual examination method involved examination of the terminal and all structures beginning in the terminal and working down through the plant. Adults of $S$. syriacus and $C$. undecimpunctata on leaves and stems also were recorded on 10 plants selected randomly during the examination.

\section{Whole plant:}

The sample unit consisted of two plants chosen randomly from interior rows of a Soybean plot. A white cylindrical bag of nylon $(1 \mathrm{~m}$ diameter and $1.5 \mathrm{~m}$ long) with a drawstring in each end was lowered over the plant and folded flat on the ground so thin it surrounded the base of the plant. The 
lower drawstring was tightened around the base of plant and the plant was cut in ground level and the bag containing the plant and insects was taken to laboratory. The bag and plants were frozen to kill the insects and then plants and bag were examined and counted all the insects (Byerly et al., 1978).

\section{Sweep-net:}

Hundred double strokes were taken weekly from plants. Each collected sample was put into plastic bags and transferred to the laboratory. Specimens were anaesthetized by diethyl ether and examined. Adults of $S$. syriacus and $C$. undecimpunctata were counted.

\section{Stinistical analysis:}

Mean values for counts of $S$. syriacus and $C$. undecimpunctata for all sampling methods were determined using analysis of variance (ANOVA) (CoStat, 2004).

The level of precision per unit of cost (Buntin, 1994) was compared among the sampling methods. Relative variation (RV) was used to measure the precision of the sampling method. RV was calculated as the percentage of mean standard error relative to the mean:

$$
\mathrm{RV}=(\mathrm{SE} / m)^{*} 100
$$

Where SE is the standard error of the sample mean and $m$ is the sample mean. Therefore, a smaller RV indicated greater precision. Southwood (1978) reported thin RV $\leq 25$ was suitable for extensive sampling programs. Relative net precision (RNP) was calculated and used to measure the efficiency of the sampling method (Buntin1994). RNP is measure thin equally considers the precision of the sampling method and its cost typically expressed in labor time. It was calculated as follows:

$$
\mathrm{RNP}=[1 /(\mathrm{RVm})(\mathrm{C})]^{\star} 100
$$

Where $R V m$ is the mean relative variation and $C$ is the cost to process one sample. Cost values were determined by averaging the time required to collect by averaging the time required to collect and count.

\section{RESULTS AND DISCUSSION}

\section{Scymnus syriacs}

As shown in Table (1), the count of predator, S. syriacus was highly significantly effect by sampling methods.

Sweep-net count more significant adults of $S$. syriacus than the other sampling methods during 2008 and 2009 seasons (Figure 2). These findings agree with the result of Parajulee and Slosser (2003) who pointed out the sticky traps captured significantly more of Hippodamia convergens and Scymnus loewii and greater capture efficiency and more affectively detected lady beetles compared with vacuum sampler. Furthermore, in 2008 season, there were no significant notes between one sided sticky trap and whole-plant. In addition, there was no significant between Cylinder sticky trap and two-sided sticky trap. But, in 2009 season, there was no significant between Cylinder sticky, one sided sticky traps, and visual examination. 
Abdel-Salam, A. H. et al.

Data in Figure (1) showed the relative population trends of $S$. syriacus estimated with cylinder sticky trap, two-sided sticky trap, one sided sticky trap, whole-plant, sweep-net, and visual examination.

Table (1): One way analysis of variance (ANOVA) for the impact of sampling method on the numbers of $S$. syriacus during seasons of 2008 and 2009 in Mansoura district.

\begin{tabular}{|c|c|c|c|c|c|}
\hline Factor & Sum of squares & $\begin{array}{c}\text { Degrees of } \\
\text { freedom }\end{array}$ & $\begin{array}{c}\text { Mean } \\
\text { square }\end{array}$ & F. Test & P \\
\hline \multicolumn{6}{|c|}{$\mathbf{2 0 0 8}$} \\
\hline Method & 1190.61 & 5 & 238.12 & 12.82 & $.0000^{\text {*** }}$ \\
\hline Error & 1225.16 & 66 & 18.563 & & \\
\hline \multicolumn{6}{|c|}{2009} \\
\hline Method & 589.20 & 5 & 117.8 & 5.2244 & $.0004^{\text {*** }}$ \\
\hline Error & 1488.70 & 66 & 22.55 & & \\
\hline
\end{tabular}

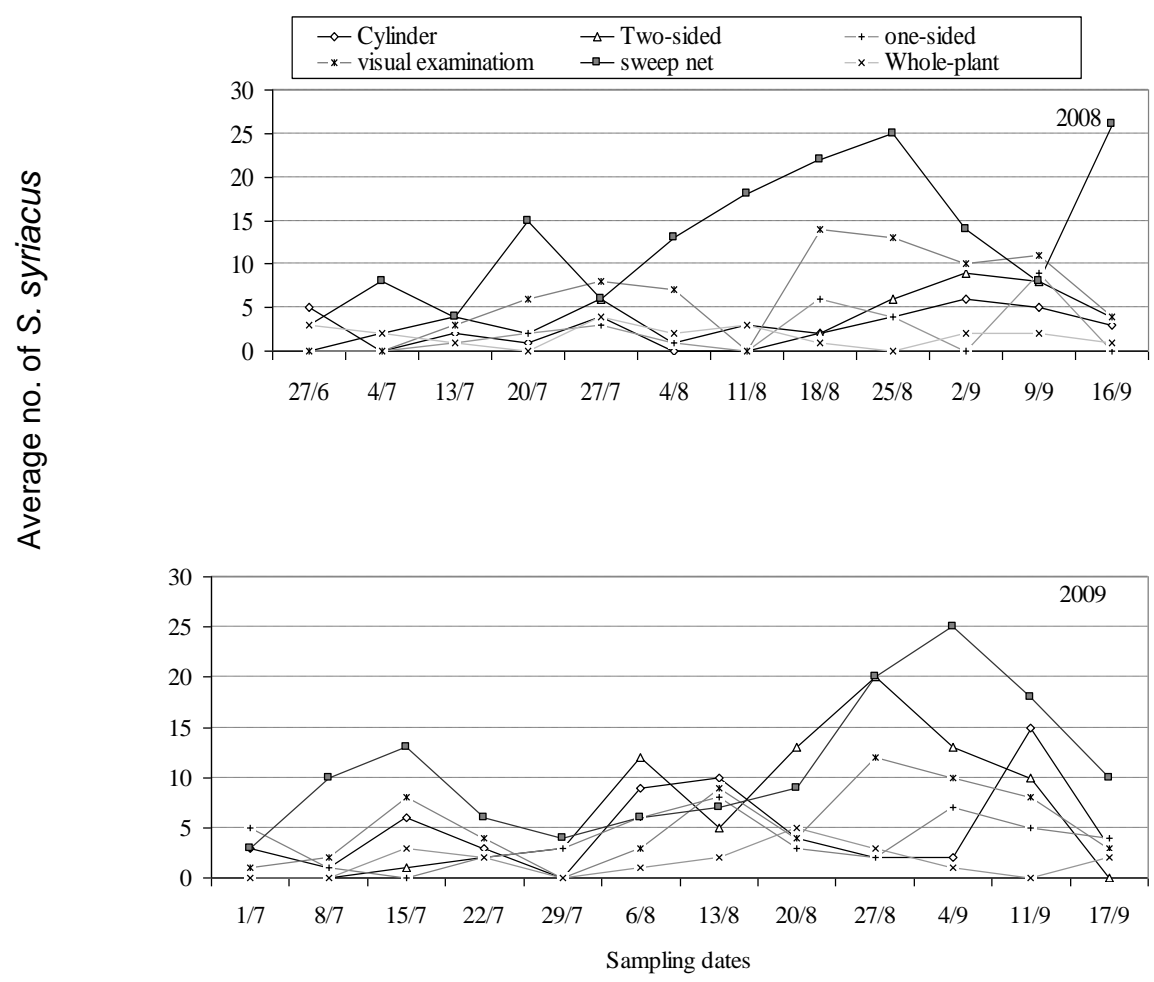

Figure (1): Relative population trends of $S$. syriacus estimated with cylinder sticky trap, two-sided sticky trap, one-sided sticky trap, whole-plant, sweep-net and visual examination on soybean plants during 2008 and 2009 seasons in Mansoura district. 
All sampling methods indicated similar population trends throughout the two seasons. For all methods, adult populations were low early and increase liner during 2008 and 2009 seasons. The relative variation of the sweep-net and one-sided sticky trap methods were significantly less than of the other four methods for sampling $S$. syriacus (Table 2). Therefore, it is the optimum sampling methods and indicated greater precision for sampling $S$. syriacus. Sweep-net recorded the highest RNP compared with the other five sampling methods. This indicated thin the sweep-net is the greater sampling efficiency. Parajulee and Slosser (2003) also reported increasing in capture efficiency of sticky trap sample for $\mathrm{S}$. syriacus compared with the vacuum sampler. Stephens and Losey (2004) also reported thin the sticky cards caught significantly more coccinellids than sweep-net and visual searching.

During the course of this study, only six sampling methods capture the predator, S. syriacus. Percent of sampling methods capture to $S$. syriacus on soybean plants during 2008 and 2009 seasons is shown in Figure (3).

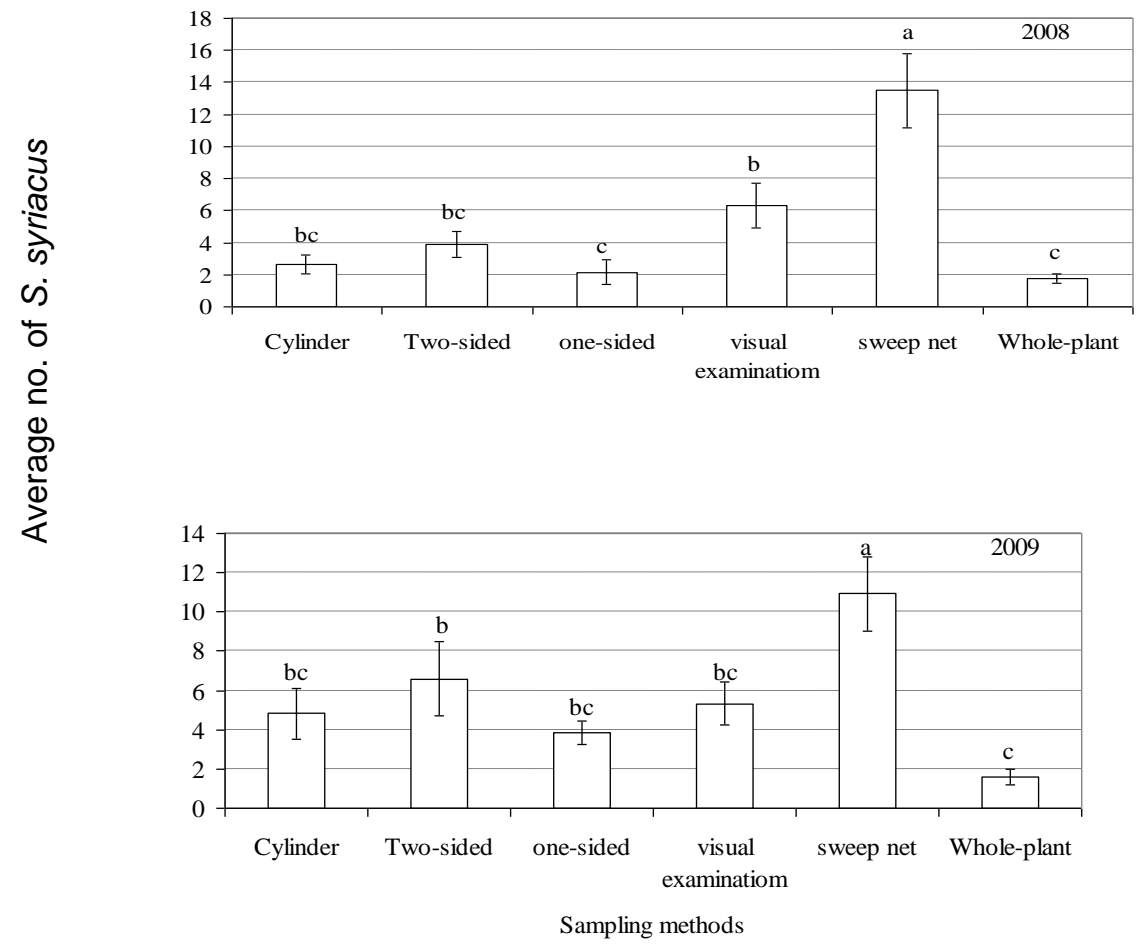

Figure (2): Mean number \pm SE of $S$. syriacus adults collected with cylinder sticky trap, two-sided sticky trap, one-sided sticky trap, whole-plant, sweep-net, and visual examination on soybean plants during 2008 and 2009 seasons in Mansoura district. 

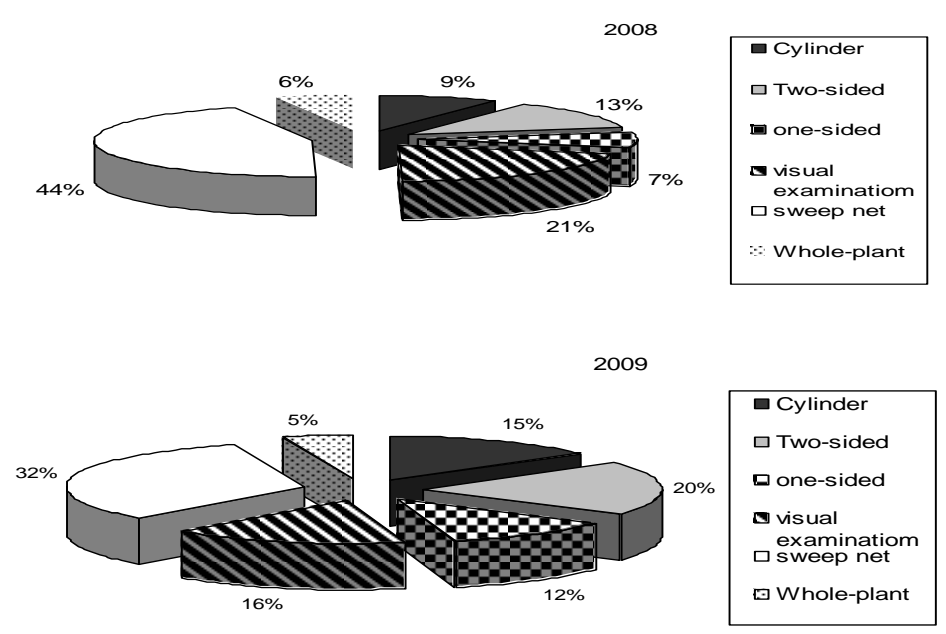

Figure (3): A comparison of percent of sampling methods capture to $S$. syriacus on soybean plants during 2008 and 2009 seasons in Mansoura district.

Table (2): Mean number of S. syriacus \pm SE, relative variation (R.V.), sampling cost (C), and relative net precision (R.N.P.) for six sampling technique on soybean plants during 2008 and 2009 seasons in Mansoura district.

\begin{tabular}{|c|c|c|c|c|}
\hline Sampling methods & Means \pm SE & R.V & C & R.N.P \\
\hline \multicolumn{5}{|c|}{$\mathbf{2 0 0 8}$} \\
\hline Cylinder & $2.66 \pm 0.6$ & 22.55 & 0.016 & 277.77 \\
\hline Two-sided & $3.91 \pm 0.8$ & 20.46 & 0.016 & 305.80 \\
\hline One-sided & $2.16 \pm 0.8$ & 20.46 & 0.014 & 349.60 \\
\hline Visual examination & $6.33 \pm 1.4$ & 22.116 & 0.027 & 167.50 \\
\hline Sweep-net & $13.5 \pm 2.3$ & 13.03 & 0.015 & 400.00 \\
\hline Whole-plant & $1.75 \pm 0.3$ & 17.14 & 0.017 & 344.80 \\
\hline \multicolumn{5}{|c|}{2009} \\
\hline Cylinder & $4.83 \pm 1.3$ & 26.91 & 0.018 & 208.33 \\
\hline Two-sided & $6.58 \pm 1.9$ & 28.875 & 0.017 & 204.8 \\
\hline One-sided & $3.83 \pm 0.6$ & 15.66 & 0.015 & 434.78 \\
\hline Visual examination & $5.33 \pm 1.1$ & 20.637 & 0.028 & 173.30 \\
\hline Sweep-net & $10.91 \pm 1.9$ & 17.41 & 0.016 & 359.70 \\
\hline Whole-plant & $1.58 \pm 0.4$ & 25.315 & 0.015 & 263.85 \\
\hline
\end{tabular}

\section{2- Coccinella undecimpunctata}

Results in Table (2) showed one way analysis of variance (ANOVA) for the impact of sampling methods on the numbers of $C$. undecimpunctata. The count of $C$. undecimpunctata was highly significantly effect by sampling methods in 2008 and 2009 seasons. Data in Figure (4) indicated that there were considerable changes in the total number of the insect caught with all sampling methods. Visual examination count more insect than sweep-net and 
whole-plant during 2008 and 2009 seasons. Population estimated with visual examination recorded three peaks in the $3^{\text {rd }}$ week of July, $2^{\text {nd }}$ week of August, and $1^{\text {st }}$ week of September but the population caught with seep-net peaked in the $4^{\text {th }}$ week July, $1^{\text {st }}$ week of August, and $1^{\text {st }}$ week of September, but the population caught with whole-plant peaked in $4^{\text {th }}$ week June, $4^{\text {th }}$ week of July, and $1^{\text {st }}$ week August during 2008 seasons. Moreover, in 2009 season, the population estimated with visual examination recorded two peaks in the $1^{\text {st }}$ week of August and $2^{\text {nd }}$ week of September but the population caught with sweep-net peaked in the $4^{\text {th }}$ week July, $4^{\text {th }}$ week of August, and $3^{\text {rd }}$ week of September. Meanwhile, the population caught with whole-plant peaked in $2^{\text {nd }}$ week July, and $3^{\text {rd }}$ week of August during 2008 season.

Table (3): One way analysis of variance (ANOVA) for the impact of sampling method on the numbers of $C$. undecimpunctata during seasons of 2008 and 2009 in Mansoura district.

\begin{tabular}{|c|c|c|c|c|c|}
\hline Factor & $\begin{array}{c}\text { Sum of } \\
\text { squares }\end{array}$ & $\begin{array}{c}\text { Degrees of } \\
\text { freedom }\end{array}$ & $\begin{array}{c}\text { Mean } \\
\text { square }\end{array}$ & F. Test & P \\
\hline \multicolumn{7}{|c|}{2008} \\
\hline Method & 110.72 & 2 & 55.36 & 10.56 & $0.000^{* * *}$ \\
\hline Error & 172.91 & 33 & 5.23 & & \\
\hline \multicolumn{7}{|c|}{2009} \\
\hline Method & 70.22 & 2 & 35.11 & 8.7117 & $0.000^{* * *}$ \\
\hline Error & 133 & 33 & 4.03 & & \\
\hline
\end{tabular}

Table (4): Mean number \pm SEM of $C$. undecimpunctata, relative variation (R.V.), sampling cost (C), and relative net precision (R.N.P.) for three sampling technique of $C$. undecimpunctata on soybean plants during 2008 and 2009 seasons in Mansoura district.

\begin{tabular}{|} 
Sampling methods & Means \pm SE & R.V & C & R.N.P \\
\hline \multicolumn{5}{|c|}{$\mathbf{2 0 0 8}$} \\
\hline Visual examination & $5.5 \pm 0.6$ & 10.90 & 0.033 & 277.77 \\
\hline Sweep-net & $2.83 \pm 0.8$ & 28.268 & 0.033 & 107.50 \\
\hline Whole-plant & $1.25 \pm 0.3$ & 24 & 0.033 & 126.58 \\
\hline \multicolumn{5}{|c|}{2009} \\
\hline Visual examination & $4.16 \pm 0.4$ & 9.61 & 0.033 & 322.58 \\
\hline Sweep-net & $1.83 \pm 0.8$ & 43.715 & 0.033 & 69.44 \\
\hline Whole-plant & $0.83 \pm 0.3$ & 36.14 & 0.033 & 84.03 \\
\hline
\end{tabular}

Data in Figure (5) showed the mean number \pm SE of adult $C$. undecimpunctata collected with whole-plant, sweep-net, and visual examination. There were significant differences between sampling methods. Visual examination had the most adult of insect during the two seasons. Moreover, there were no significant differences between whole-plant and sweep-net.

Visual examination recorded the highest percent of capture $C$. undecimpunctata 2008 and 2009 (Figure 6). Visual examination had the lowest associated RV value in the first and second seasons (10.90 and 9.61, respectively). Moreover, the sweep-net had the highest calculated RV value in the 2008 and 2009 seasons. Our results were similar to those reported from visual counts on grain sorghum by Michels and Behle (1992). Visual 
Abdel-Salam, A. H. et al.

examination had the highest calculated RNP value (most efficient) compared with all other sampling methods in the first and second seasons (Table 2). Knutson et al. (2008) showed that sweep-net was the most cost reliable for sampling adults of Coccinellidae.

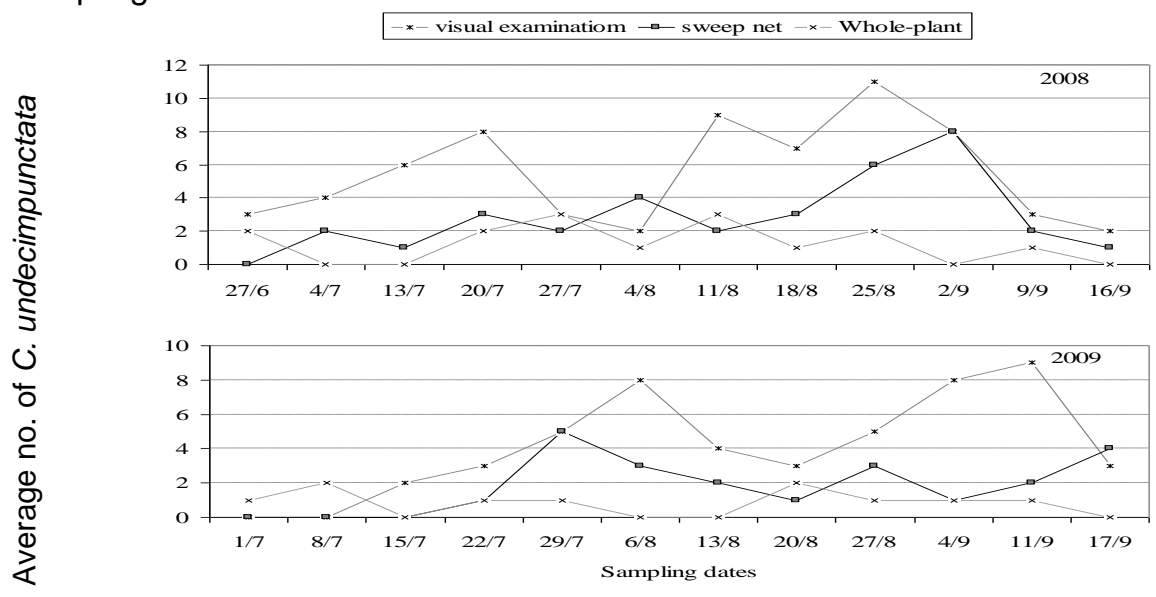

Figure (4): Relative population trends of $C$. undecimpunctata estimated with whole-plant, sweep-net, and visual examination on soybean plants during 2008 and 2009 seasons in Mansoura district.

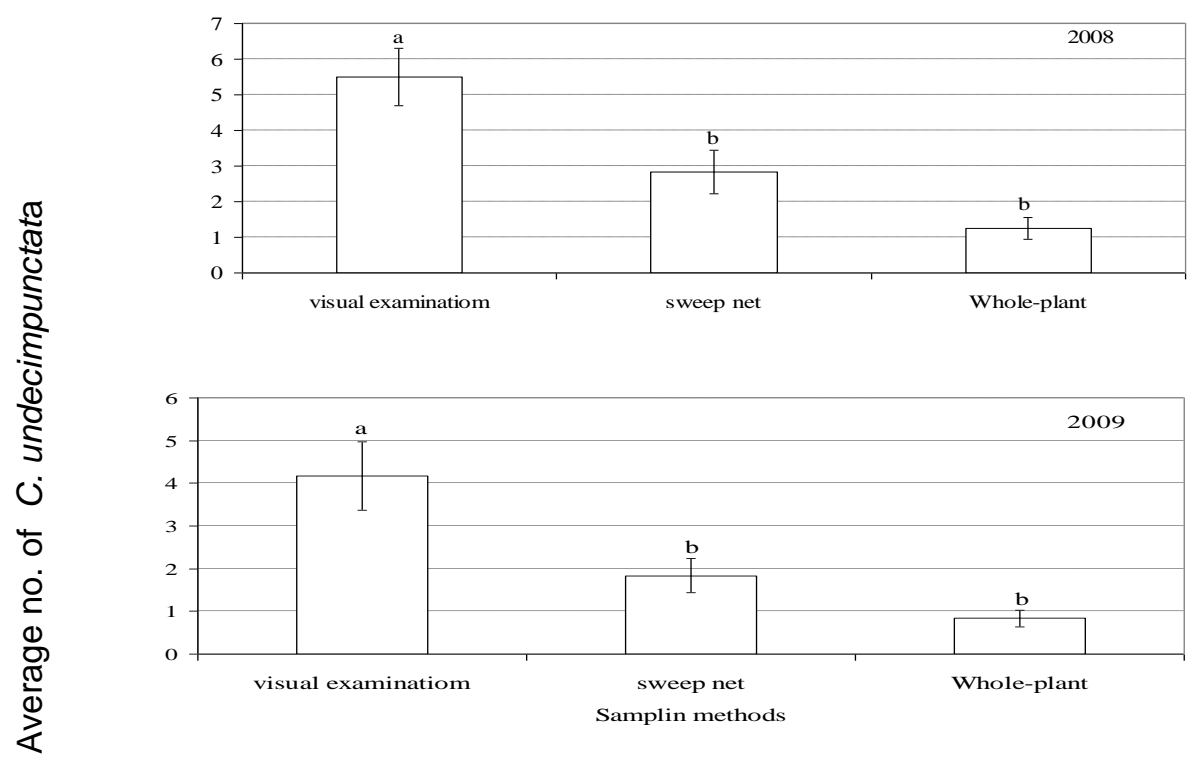

Figure (5): Mean number \pm SE of adult $C$. undecimpunctata collected with whole-plant, sweep-net, and visual examination on soybean plants during 2008 and 2009 seasons in Mansoura district. 

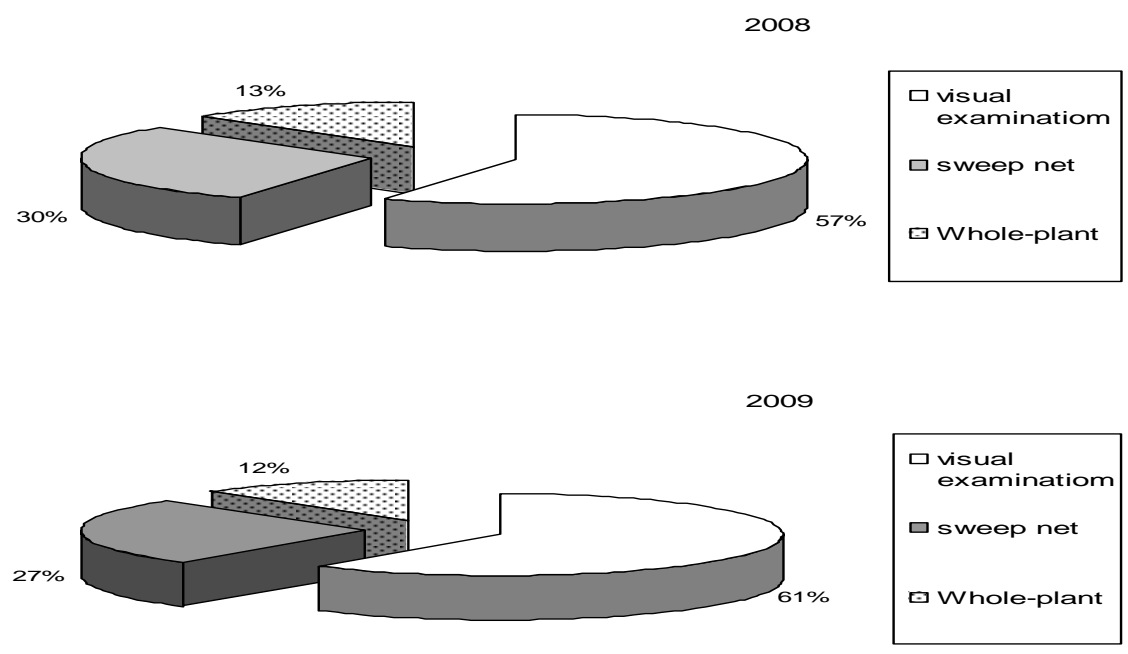

Figure (6): A comparison of percent of sampling methods capture to $C$. undecimpunctata on soybean plants during 2008 and 2009 seasons in Mansoura district.

\section{REFERENCES}

Buntin, G. D. (1994). Developing a primary sampling program, pp. 99-115. In L.P. Pedigo and G. D. Buntin [eds.], Handbook of sampling methods for arthropods in agriculture. CRC, Boca Raton, Fl.

Byerly, K. F., A. P. Gutierrez, R. E. Jones and R.F. Luck. (1978). A comparison of sampling methods for some arthropod population in cotton. Hilgardia 46: 257-282.

CoStat Software. 2004. CoStat. www.cohort.com. Monterey, California, USA.

El-Adl, M. A.; A. A. Ghanim and A. A. A. Said (1988). Field trials on predatory insects inhabiting soybean and their susceptibility to some insecticides and their combinations with two IGR's IN Mansoura, Egypt. J. Agric. Sci. Mansoura Univ. 13:1427-1434.

Knutson, A. E; M.A Muegge; L.T. Wilson and S. E. Naranjo (2008). Evaluation of sampling methods and development of sample plans for estimating predator densities in cotton. J. Econ. Entomol. 101(4): 1501-1509.

Mensah, R. K. (1997). Yellow traps can be used to monitor population of Coccinella transversalis (F.) and Adalia bipunctina (L.) (Coleoptera: Coccinellidae) in cotton crops. Aust. J. Entomol. 36:377-381.

Michels, G.J. ,Jr. and R.W. Behle (1992). Evaluation of sampling methods for lady beetles (Coleoptera: Coccinellidae) in grain sorghum. J. Econ. Entomol., 85(6): 2251-2257

Parajulee, M. N; and T. W. Phillips. (1995). Seasonal abundance and spatial patterns of the predator, Lyctocoris campestris in stored corn. Entomol. Exp. Appl., 75:33-42.

Parajulee, M. N; and J. E. Slosser (2003). Potential of yellow sticky traps for lady beetle survey in cotton. J. Econ. Entomol., 96(1): 239-245. 


\section{Abdel-Salam, A. H. et al.}

Parajulee, M. N; R. Montandon and J. E. Slosser. (1997). Relay intercropping to enhance abundance of insect predators of cotton aphid (Aphis gossypii Glover) in Texas cotton. Int. J. Pest Mange., 43:227-232.

Southwood, T. R. E. (1978). Ecological methods with particular reference to the study of insect population, $2^{\text {nd }}$ ed. Chapman Hall, London, United Kingdom.

Slosser, J. E., W. E. Pinchak, and D. R. Rummel. (1998). Biotic and a biotic regulation of Aphis gossypii Glover in west Texas dry land cotton. Southwest. Entomol. 23:31-65.

Stephens, E. J. and J. E. Losey. (2004). Comparison of sticky cards, visual and sweep sampling of coccinellid populations in alfalfa. Environ. Entomol., 33(3): 535-539.

Weston, P. A., and R. J. Barney (1998). Comparison of three trap types for monitoring insect population in stored grains. J. Econ. Entomol., 91:14491457.

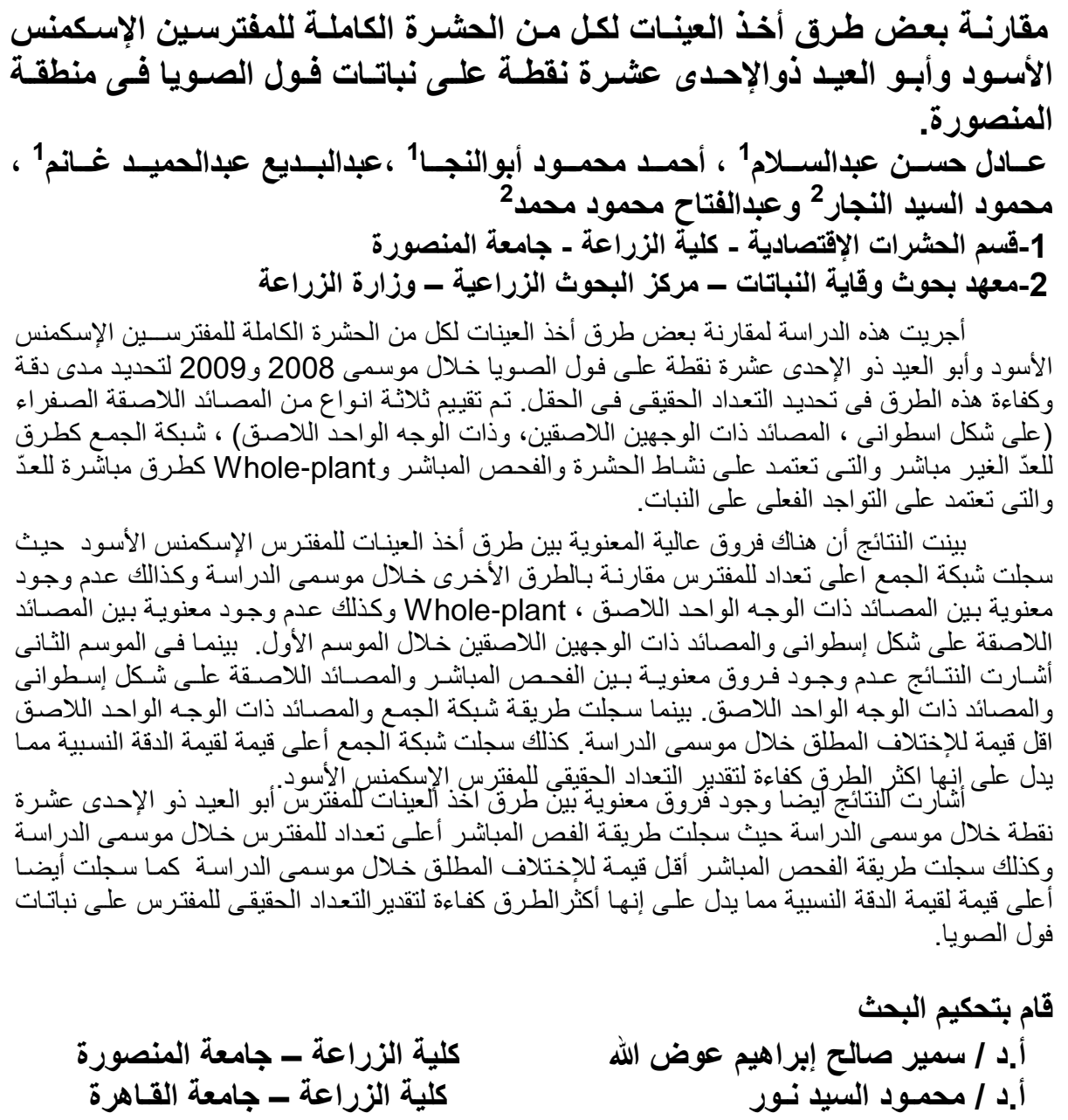

